\title{
Biological sex and social gender: challenges for preventive and social medicine
}

\author{
Dr. Doyal is professor of health and social care at the School for Policy Studies, University of Bristol
}

Over the last few years there has been a growing interest in the impact of sex and gender on health and health care. Policy makers and practitioners are being asked to make their services more "gender sensitive" while researchers are being called upon to pay equal attention to the needs of women and men. This editorial offers a brief introduction to some of the challenges that will need to be met if an appropriate evidence base for this more equitable approach to health care is to be achieved.

The first challenge is a conceptual one. There continues to be a lack of clarity among biomedical researchers about the distinction between sex and gender. Too often the two are used interchangeably. However in the correct usage, the term "sex" refers to the biological differences between women and men while the term "gender" refers to the social differences (Doyal 2001). Unless this distinction is clearly understood it will be hard for researchers to make proper sense of any observed differences between women and men or to plan appropriate interventions.

But it is not enough to recognise the distinction between biological sex and social gender as determinants of health. Researchers must also face a second challenge of how to integrate these very different factors into the design of their studies. Concerns of this kind have received particular attention in the U.S. where commentators have highlighted the male bias in both epidemiological research and clinical trials (Kahn et al. 1998). This has been especially evident in the area of heart disease. In developed countries this is the single most important cause of death in women over 55. Yet many of the major studies that provide the knowledge base for their treatment were based on all-male samples (Mastroianni et al. 1994).

In response to evidence of this bias, the U.S. government passed a number of measures designed to "mainstream" sex and gender issues in medical research (Mastroianni et al.
1994). Most important of these was a law passed in 1994 which prevented scientists from receiving federal funding for their work unless they included appropriate numbers of women and men in the sample. Studies had to include male and female groups of sufficient size to ensure that any statistically significant differences between them could be detected. And researchers were expected to include the search for such differences as part of their overall analysis. Important lessons can be learned from these policies adopted in the USA. But again, the inclusion of more equal numbers of women and men and the search for differences between them takes us only part of the way. The third challenge for medical researchers comes when and if such differences are identified. The question which then has to be addressed is how such observed variations are to be explained. Are they biological or social or (more likely) a combination of both? In their attempts to solve empirical puzzles of this kind, medical researchers are increasingly being required to think in more flexible and creative ways. But many are finding that their capacity to do this is constrained by their disciplinary background.

A biomedical training is a preparation for exploring the biological. But as we have seen, the concept of gender is derived from the social sciences. Moreover the social reality of gender is not always amenable to the statistical methods usually used to explain the biological. Epidemiologists and other medical researchers will therefore need to think critically about their own approaches and be prepared to work collaboratively with others if the biological and the social dimensions of human health are to be brought closer together (Krieger 2000).

It is clear that in the coming decades some of the most exciting work in health research will be interdisciplinary in approach and those already involved in social and preventive medicine are well placed to contribute to these developments.

Soz.- Präventivmed. 48 (2003) 207-208

0303-8408/03/040207-02

DOI 10.1007/s00038-003-3057-8

(c) Birkhäuser Verlag, Basel, 2003 
The growing interest in the links between the biological and the social offers unique opportunities to work with colleagues in the social sciences across traditional disciplinary boundaries. And the mainstreaming of sex and gender into health research should be an important part of that process. If this can be achieved it will promote better science while at the same time contributing to the promotion of gender equity both in health care and in the wider society (Doyal 2000).

\section{References}

Doyal L (2000). Gender equity in health: debates and dilemmas. Soc Sci Med 51: 931-9.

Doyal L (2001). Sex, gender and health: the need for a new approach. BMJ 7320: 1061-3.

Kahn J, Mastroianni A, Sugarman J (1998). Beyond consent: seeking justice in research Oxford: Oxford University Press.
Krieger $N(2000)$. Epidemiology and social sciences: towards a critical reengagement in the 21st century. Epidemiol Rev 11: 155-63.

Mastroianni A, Faden R, Federman D (1994).

Women and health research: ethical and legal issues of including women in clinical trials, vol 1. Washington: National Academy Press .
Address for correspondence

Prof. Lesley Doyal

Centre for Health and Social Care

School for Policy Studies

University of Bristol

8 Priory Road

UK-Bristol BS8 1TZ

e-mail: L.Doyal@bristol.ac.uk

(1) To access this journal online:

(2P) http://www.birkhauser.ch 